\title{
Evolving gallstone ileus: the gallstone as it migrates and the lessons learnt
}

\author{
Muhammad Qutayba Almerie
}

Department of General Surgery, Leeds University, St James's University Teaching Hospital, Leeds, UK

\section{Correspondence to}

Muhammad Qutayba Almerie, qalmerie@doctors.org.uk

Accepted 12 December 2015
CrossMark

To cite: Almerie MQ. BMJ Case Rep Published online: [please include Day Month Year] doi:10.1136/bcr-2015212972

\section{DESCRIPTION}

Gallstone ileus is a rare cause of bowel obstruction $(1-4 \%){ }^{1}$ It is usually preceded by cholecystitis, which facilitates the adherence of the inflamed gallbladder to the adjacent gut. If the gallbladder has an impacted gallstone, this could erode through the wall of the gallbladder into the gut, forming a cholecystoenteric fistula. As they pass through the bowels, the larger stones $(>2.5 \mathrm{~cm})$ can get impacted, mainly in the terminal ileum, causing mechanical obstruction. ${ }^{2}$ Gallstone ileus is associated with high mortality (12-17\%), largely due to the high-risk population it usually occurs in, typically elderly people with multiple comorbidities. ${ }^{3}$ Relieving the obstruction by performing an
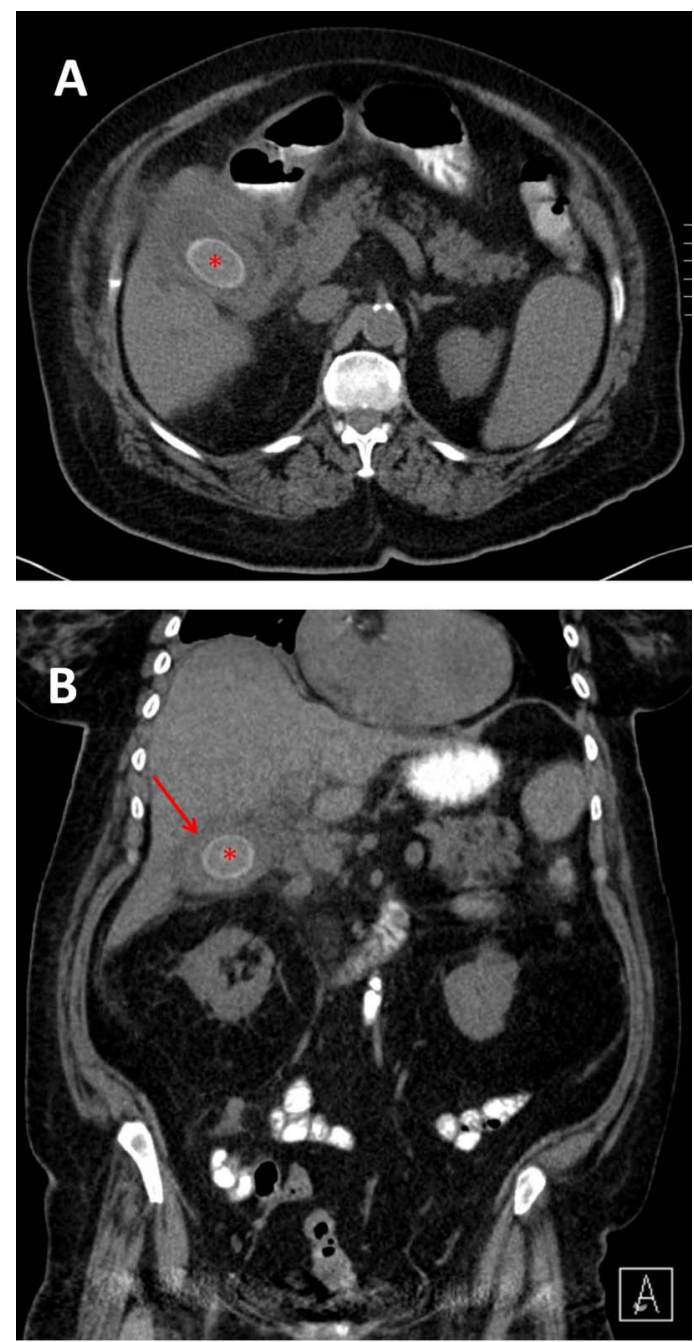

Figure 1 CT scan of the abdomen and pelvis on the first admission. Cross-sectional (A) and coronal (B) images showing a large gallstone (red asterisk) in a thick-walled gallbladder (red arrow).
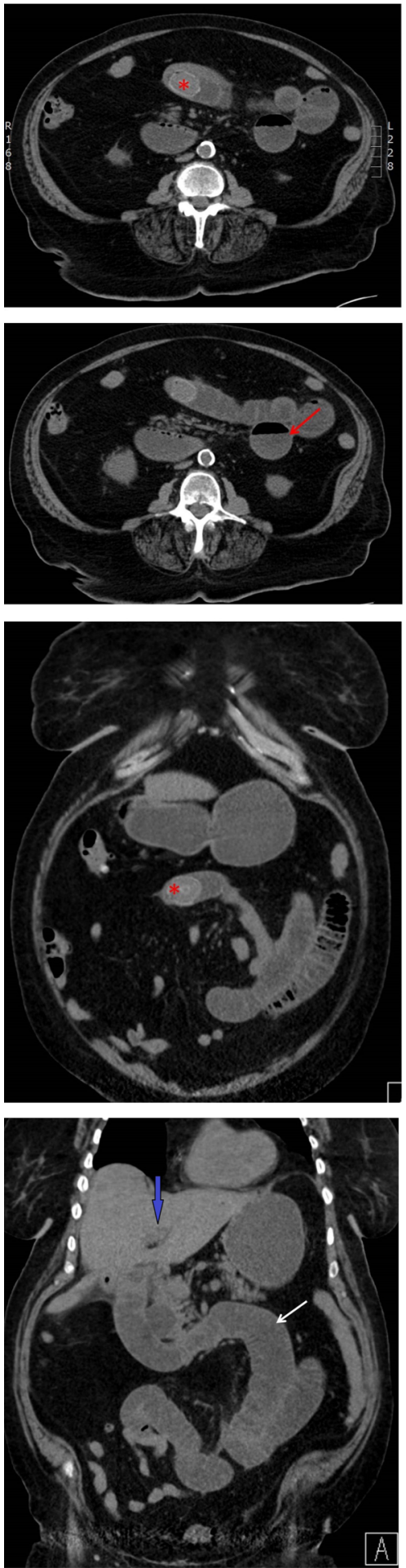

Figure 2 CT scan of the abdomen and pelvis on the second admission ( 3 weeks later). The cross-sectional and coronal images showing features of Rigler's triad of gallstone ileus: (1) a gallstone in the small bowel (red asterisk), (2) dilated loops of the small bowel (white and red arrows) and (3) pneumobilia (blue arrow). 

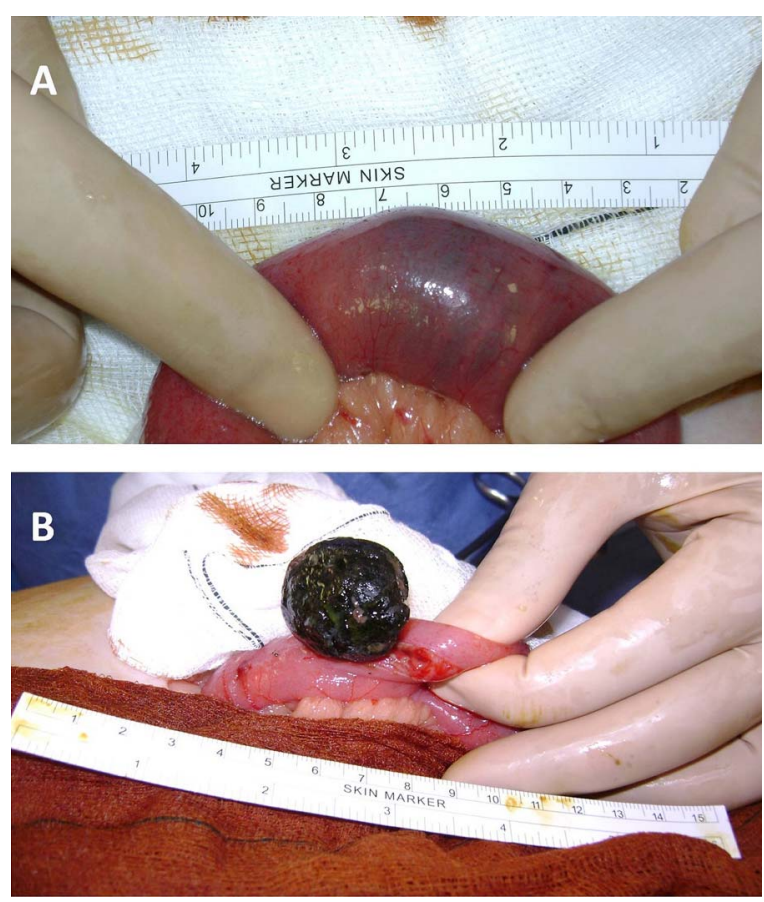

Figure 3 (A) The intraoperative images of the small bowel containing a gallstone. (B) The gallstone extracted via an enterotomy.

enterolithotomy is the common practice in these patients, while offering them a delayed cholecystectomy and fistula repair remains controversial. ${ }^{3}$ Performing a one-stage procedure (enterolithotomy, cholecystectomy and fistula repair) is associated with a high risk of complications and is thus reserved for young and fit patients. ${ }^{3}$

We report an interesting case of gallstone ileus as it developed in an 88-year-old woman. The patient was admitted with acute cholecystitis and a CT scan showed a $3 \mathrm{~cm}$ stone in a thickwalled gallbladder (figure 1). She was successfully treated conservatively and a decision was made not to offer her an elective cholecystectomy as she was deemed unfit for the operation.
Interestingly, only 3 weeks later, the patient was readmitted with a 3-day history of severe colicky abdominal pain and vomiting. An urgent CT scan of the abdomen and pelvis showed that the recently found large gallstone had migrated into the gut and impacted in the ileum causing small bowel obstruction (figure 2).

The patient was taken to the theatre the same day, and underwent a laparotomy and extraction of the gallstone via enterotomy (figure 3). She had an uneventful recovery and remained well at 3-month follow-up.

\section{Learning points}

- Gallstone ileus should be considered in all elderly patients with significant history of cholelithiasis presenting with features of bowel obstruction.

- The decision to expectantly manage patients with gallstones based on their fitness level should be carefully taken particularly in those with known large gallstones, as related complications, including gallstone ileus, may be fatal in these frail patients.

- The mainstay of treatment in unfit patients is to relieve the bowel obstruction via enterotomy and avoid a prolonged operation.

Competing interests None declared.

Patient consent Obtained.

Provenance and peer review Not commissioned; externally peer reviewed.

\section{REFERENCES}

1 Ayantunde AA, Agrawal A. Gallstone ileus: diagnosis and management. World J Surg 2007:31:1292-7.

2 Abou-Saif A, Al-Kawas FH. Complications of gallstone disease: Mirizzi syndrome, cholecystocholedochal fistula, and gallstone ileus. Am J Gastroenterol 2002;97:249-54.

3 Ravikumar R, Williams JG. The operative management of gallstone ileus. Ann R Coll Surg Engl 2010;92:279-81.

Copyright 2015 BMJ Publishing Group. All rights reserved. For permission to reuse any of this content visit

http://group.bmj.com/group/rights-licensing/permissions.

BMJ Case Report Fellows may re-use this article for personal use and teaching without any further permission.

Become a Fellow of BMJ Case Reports today and you can:

- Submit as many cases as you like

- Enjoy fast sympathetic peer review and rapid publication of accepted articles

- Access all the published articles

- Re-use any of the published material for personal use and teaching without further permission

For information on Institutional Fellowships contact consortiasales@bmjgroup.com

Visit casereports.bmj.com for more articles like this and to become a Fellow 